\title{
Article \\ BiP Heterozigosity Aggravates Pathological Deterioration in Experimental Amyotrophic Lateral Sclerosis
}

\author{
Marta Gómez-Almería 1,2,3, Sonia Burgaz 1,2,3 , Carlos Costas-Insua ${ }^{2,3,4}$ (D), Carmen Rodríguez-Cueto ${ }^{1,2,3}$, \\ Irene Santos-García 1,2,3 ${ }^{D}$, Ignacio Rodríguez-Crespo 2,3,4, Concepción García 1,2,3, Manuel Guzmán 2,3,4 , \\ Eva de Lago ${ }^{1,2,3}$ (D) and Javier Fernández-Ruiz ${ }^{1,2,3, * \mathbb{D}}$
}

1 Instituto Universitario de Investigación en Neuroquímica, Departamento de Bioquímica y Biología Molecular Facultad de Medicina, Universidad Complutense, 28040 Madrid, Spain; margom27@ucm.es (M.G.-A.); soniabur@ucm.es (S.B.); carc@med.ucm.es (C.R.-C.); isantosg@ucm.es (I.S.-G.); conchig@med.ucm.es (C.G.); elagofem@ucm.es (E.d.L.)

2 Centro de Investigación Biomédica en Red de Enfermedades Neurodegenerativas (CIBERNED), 28040 Madrid, Spain; cacostas@ucm.es (C.C.-I.); jirodrig@quim.ucm.es (I.R.-C.); mguzman@quim.ucm.es (M.G.)

3 Instituto Ramón y Cajal de Investigación Sanitaria (IRYCIS), 28040 Madrid, Spain

4 Instituto Universitario de Investigación en Neuroquímica, Departamento de Bioquímica y Biología Molecular, Facultad de Biología, Universidad Complutense, 28040 Madrid, Spain

* Correspondence: jjfr@med.ucm.es; Tel.: +34-913941450

\section{check for} updates

Citation: Gómez-Almería, M.; Burgaz, S.; Costas-Insua, C.; Rodríguez-Cueto, C.; Santos-García, I.; Rodríguez-Crespo, I.; García, C.; Guzmán, M.; de Lago, E.; Fernández-Ruiz, J. BiP Heterozigosity Aggravates Pathological Deterioration in Experimental Amyotrophic Lateral Sclerosis. Int. J. Mol. Sci. 2021, 22, 12533. https:// doi.org/10.3390/ijms222212533

Academic Editor: Julia Costa

Received: 21 June 2021

Accepted: 19 November 2021

Published: 20 November 2021

Publisher's Note: MDPI stays neutral with regard to jurisdictional claims in published maps and institutional affiliations.

Copyright: (c) 2021 by the authors. Licensee MDPI, Basel, Switzerland. This article is an open access article distributed under the terms and conditions of the Creative Commons Attribution (CC BY) license (https:// creativecommons.org/licenses/by/ $4.0 /)$.

\begin{abstract}
In the present study, we investigated the involvement of the chaperone protein BiP (also known as GRP78 or Hspa5), a master regulator of intracellular proteostasis, in two mouse models of neurodegenerative diseases: amyotrophic lateral sclerosis (ALS) and Parkinson's disease (PD). To this end, we used mice bearing partial genetic deletion of the $\mathrm{BiP}$ gene $\left(\mathrm{BiP}^{+/-}\right.$mice), which, for the ALS model, were crossed with mutant SOD1 (mSOD1) transgenic mice to generate mSOD1/ $\mathrm{BiP}^{+/-}$ double mutant mice. Our data revealed a more intense neurological decline in the double mutants, reflected in a greater deterioration of the neurological score and rotarod performance, with also a reduced animal survival, compared to mSOD1 transgenic mice. Such worsening was associated with higher microglial (labelled with Iba-1 immunostaining) and, to a lesser extent, astroglial (labelled with GFAP immunostaining) immunoreactivities found in the double mutants, but not with a higher loss of spinal motor neurons (labelled with Nissl staining) in the spinal cord. The morphological analysis of Iba-1 and GFAP-positive cells revealed a higher presence of activated cells, characterized by elevated cell body size and shorter processes, in double mutants compared to mSOD1 mice with normal BiP expression. In the case of the PD model, $\mathrm{BiP}^{+/-}$mice were unilaterally lesioned with the parkinsonian neurotoxin 6-hydroxydopamine (6-OHDA). In this case, however, we did not detect a greater susceptibility to damage in mutant mice, as the motor defects caused by 6-OHDA in the pole test and the cylinder rearing test, as well as the losses in tyrosine hydroxylase-containing neurons and the elevated glial reactivity (labelled with CD68 and GFAP immunostaining) detected in the substantia nigra were of similar magnitude in $\mathrm{BiP}^{+/-}$mice compared with wildtype animals. Therefore, our findings support the view that a dysregulation of the protein $\mathrm{BiP}$ may contribute to ALS pathogenesis. As BiP has been recently related to cannabinoid type- $1\left(\mathrm{CB}_{1}\right)$ receptor function, our work also opens the door to future studies on a possible link between $\mathrm{BiP}$ and the neuroprotective effects of cannabinoids that have been widely reported in this neuropathological context. In support of this possibility, preliminary data indicate that $\mathrm{CB}_{1}$ receptor levels are significantly reduced in mSOD1 mice having partial deletion of BiP gene.
\end{abstract}

Keywords: cannabinoids; $\mathrm{CB}_{1}$ receptors; $\mathrm{BiP}$ interactor protein; $\mathrm{BiP}^{+/-}$mice; $\mathrm{mSOD} 1$ mice; amyotrophic lateral sclerosis; spinal cord; Parkinson's disease 


\section{Introduction}

Phytocannabinoids, the active constituents of Cannabis plant, as well as endocannabinoids and synthetic cannabinoids, have been proposed as promising neuroprotective agents, a property derived from their pleiotropism and ability to activate numerous cytoprotective targets within the endocannabinoid system, but also outside this signaling system (reviewed in [1]). Such neuroprotective potential has been preclinically investigated in accidental brain damage (e.g., stroke, brain trauma, spinal injury) and, in particular, in chronic progressive disorders (e.g., Alzheimer's disease, amyotrophic lateral sclerosis (ALS), Parkinson's disease (PD), Huntington's disease, and others) (reviewed in [2,3]).

An important part of these neuroprotective properties described for cannabinoids have been related to the activation of the type- 1 cannabinoid $\left(\mathrm{CB}_{1}\right)$ receptor (reviewed in $[2,3]$ ). This receptor is predominantly located in neurons in the CNS, which facilitates its role in the control of excitotoxic damage in glutamatergic neurons [4], as well as a possible contribution in the autophagy-mediated elimination of protein aggregates [5]. Data supporting $\mathrm{CB}_{1}$ receptor-mediated neuroprotective effects have been collected in experimental models of Alzheimer's disease [6-8], Huntington's disease [4,9-12], multiple sclerosis [13,14], PD [15-17], and ALS [18-20]. In this last disorder, $\mathrm{CB}_{1}$ receptor activation was found to protect murine spinal cord neurons in vitro against kainate-induced neurotoxicity [18]. Interestingly, this receptor experiences an important reduction in spinal motor neurons in the classic murine model of ALS, based on the G93A mutation of the SOD1 gene, thus predisposing these neurons to excitotoxicity [19], a result also found in a further study measuring $C_{1}$ receptor sensitivity with neurophysiological recordings in the same experimental model [20]. In the case of $\mathrm{PD}$, studies conducted in $\mathrm{CB}_{1}$ receptor knockout mice lesioned with the parkinsonian neurotoxin 6-hydroxydopamine (6-OHDA), proved a worsening in the progression of motor defects, as well as in the development of L-DOPAinduced dyskinesia compared to wildtype mice [16]. Additional studies revealed benefits with $\mathrm{CB}_{1}$ receptor activation against inflammatory events in MPTP-lesioned mice [15].

Despite the relevance of the $\mathrm{CB}_{1}$ receptor in the neuroprotective properties of cannabinoids, the identification of the specific cellular, subcellular, and molecular mechanisms underlying this therapeutic potential is still hampered, at least in part, by the lack of knowledge on the neuron subpopulation selectivity of $\mathrm{CB}_{1}$ receptor action. $\mathrm{CB}_{1}$ receptor action may be modulated in different manners, being conceivably, among different possibilities, its association to different cytoplasmic proteins through its intracellular domains, in particular its large cytoplasmic $\mathrm{C}$-terminal domain. This includes, for example, the cannabinoid receptor-interacting protein 1a (CRIP1a), $\beta$-arrestins, or GPCR-associated sorting protein (GASP) [21]. Recently, we have purified the $\mathrm{CB}_{1}$ receptor $\mathrm{C}$-terminal domain and have conducted yeast two-hybrid experiments aimed at finding new receptor interactors [22]. This approach rendered a potential $\mathrm{CB}_{1}$ receptor-interacting protein that may be particularly attractive owing to its involvement in neurodegenerative processes: the molecular chaperone binding immunoglobulin protein (BiP), also known as 78-kDa glucose-regulated protein (GRP78) or 70-kDa heat shock protein 5 (Hspa5). This protein plays a dual role in endoplasmic reticulum stress by controlling protein folding to prevent aggregation and also by regulating the unfolded protein response (UPR) [23-25]. Its dysregulation has been related to different physiopathological conditions, including physiological and pathological brain aging, for which a reduced $\mathrm{BiP}$ function has been proposed as a predisposing factor in different chronic neurodegenerative pathologies [23].

In the present study, we investigated the involvement of a dysregulation of $\mathrm{BiP}$ in the pathogenesis of ALS by using mSOD1(G93A) transgenic mice, which were crossed with mice harboring a partial genetic deletion of the $\mathrm{BiP}$ gene $\left(\mathrm{BiP}^{+/-}\right.$mice) (Note that very early embryonic lethality occurs in $\mathrm{BiP}^{-/-}$mice [26]) to generate double mutants (mSOD1/ $\mathrm{BiP}^{+/-}$mice), in which we analyzed the progression of the pathological phenotype. We also investigated this issue in a PD model through evaluating the consequences of unilateral lesions carried out in $\mathrm{BiP}^{+/-}$mice with the parkinsonian neurotoxin 6-OHDA, again with the objective to assess neurotoxin susceptibility in these mice compared to 
wildtype animals. The hypothesis derived from both paradigms is that the neuroprotective effects associated with the activation of the $\mathrm{CB}_{1}$ receptor in experimental ALS [18-20], as well as those described in experimental PD [15-17], could be related to a modulation of $\mathrm{CB}_{1}$ receptor function by $\mathrm{BiP}$, which would be conceivable for their recently-demonstrated physical interaction [22], but this will be the objective of future work. In the present study, we wanted to set up a proof of concept that inducing ALS and/or PD pathology in mice having dysregulated $\mathrm{BiP}$ function would be followed by alterations in the progression of these two diseases.

\section{Results}

\subsection{Studies in Experimental ALS: Generation of Double Mutants ( $m S O D 1 / \mathrm{Bi}^{+/-}$Mice)}

The first objective of our study was to cross mice having partial genetic deletion of the $\mathrm{BiP}$ gene $\left(\mathrm{BiP}^{+/-}\right.$mice) with $\mathrm{mSOD} 1$ transgenic mice, a classic murine genetic model of ALS, to generate double mutants (mSOD1/ $\mathrm{BiP}^{+/-}$mice), in which we evaluated the progression of the pathological phenotype. We first analyzed the weight gain in the four genotypes which proved a trend towards a decrease in double mutants compared to the other three genotypes when animals were 11 week-old, reflected in the 2-way ANOVA (with repeated measures) statistics for the variable age $(\mathrm{F}(2,70)=6.57, p<0.01)$ and in its 2-way interaction with the variable genotype $(\mathrm{F}(6,70)=2.93, p<0.05)$, although the effect did not reach statistical significance with the post hoc analysis (Figure 1A). Similar trends at weeks 10 and 11 after birth were also evident for the animal responses in the hanging wire test (age: $F(2,70)=3.15, p=0.066$; see Figure $1 B$ ), whereas statistically significant differences were evident for the deterioration in the neurological score which was greater in double mutants at week 11 (as a trend at week 10) compared to wildtype and $\mathrm{BiP}^{+/-}$ mice (genotype: $\mathrm{F}(3,70)=5.95, p<0.005$; age: $\mathrm{F}(2,70)=15.48, p<0.0001$; 2-way interaction: $\mathrm{F}(6,70)=7.49, p<0.0001$; see Figure 1C). This was also found for the animal response in the rotarod test with the lowest times in the rod at the three ages analyzed always in the double mutants (genotype: $\mathrm{F}(3,62)=2.83$, ns; age: $\mathrm{F}(2,62)=16.41, p<0.0001$; 2-way interaction: $\mathrm{F}(6,62)=1.20, \mathrm{~ns})$, but reaching statistical significance as compared with wildtype mice only at week 11 (Figure 1D).
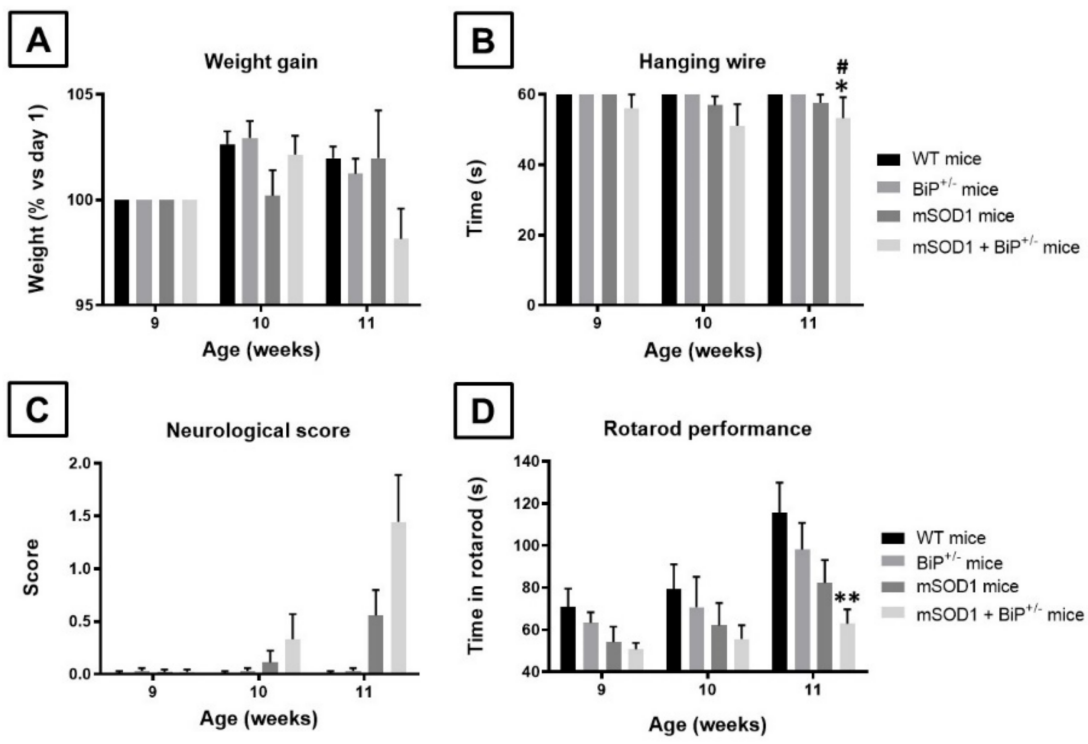

Figure 1. Weight gain (panel (A)), hanging wire response (panel (B)), neurological score (panel (C)), and rotarod performance (panel (D)) analyzed at the period of 9 to 11 weeks of age in mSOD1 transgenic and wild-type male mice with normal or partial ablation of the BiP protein. Values are means \pm SEM of 6-10 animals per group. Data were assessed by two-way analysis of variance (with repeated measures) followed by the Tukey test $\left({ }^{*} p<0.05,{ }^{* *} p<0.01\right.$ vs. WT mice; ${ }^{*} p<0.05$ vs. $\mathrm{BiP}^{+/-}$mice). 
This greater neurological worsening seen in the double mutants was also accompanied by a faster mortality compared to mutant SOD1 transgenic mice $\left(\chi^{2}=4.952, p<0.05\right.$; Figure 2A). Mortality was initiated in $\mathrm{mSOD} 1 / \mathrm{BiP}^{+/-}$mice at 15 weeks of age with all animals dying at 21 weeks of age (median survival at 140 days), whereas, in mSOD1 mice, mortality was initiated at 20 weeks with all animals dying at 23 weeks (median survival at 146 days) (Figure 2A).

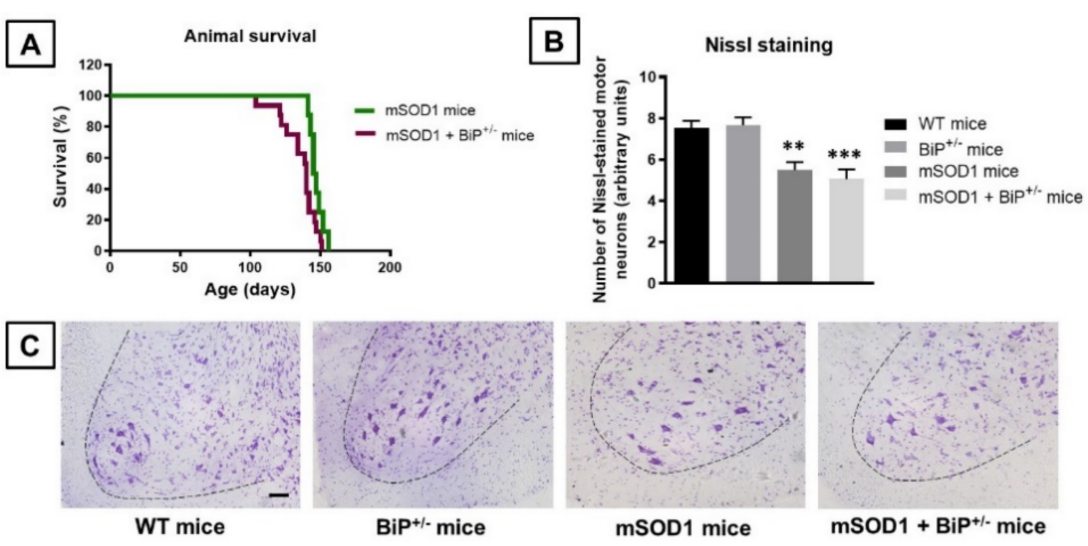

Figure 2. Analysis of animal survival (panel (A)) and of the number of Nissl-stained motor neurons (panel (B)), including representative images (panel (C); scale bar $=100 \mu \mathrm{m}$ ), in the lumbar ventral horn (marked with a dotted line) of the spinal cord in mSOD1 transgenic and wild-type male mice with normal or partial ablation of the BiP protein. In the case of Nissl staining, values are means \pm SEM of 5-7 animals per group and were assessed by one-way analysis of variance followed by the Tukey test $\left({ }^{* *} p<0.01,{ }^{* * *} p<0.005\right.$ vs. WT or $\mathrm{BiP}^{+/-}$mice). Data for animal survival were presented as a Kaplan-Meier plot and assessed by Chi-square test.

Next, we analyzed several histopathological markers in the ventral horn of the spinal cord, where the cell bodies of lower spinal motor neurons affected in ALS are located. We used Nissl staining to label these neurons, and Iba- 1 and GFAP immunofluorescence to identify microglial and astroglial cells, respectively. Our data indicated that the number of Nissl-stained motor neurons was significantly reduced in mSOD1 mice $(p<0.01)$, with a relatively similar reduction in $\mathrm{mSOD} 1 / \mathrm{BiP}^{+/-}$mice $(p<0.005)$, compared with the two control genotypes $(\mathrm{F}(3,29)=10.74, p<0.0001$; Figure $2 \mathrm{~B}, \mathrm{C})$.

Such important loss of Nissl-stained motor neurons was associated, as expected, with elevated levels of microglial reactivity (Iba-1 immunolabelling) in both mSOD1 genotypes compared to the two control groups $(\mathrm{F}(3,29)=8.90, p<0.0005$; Figure 3A,B). However, in this case, the immunoreactivity detected in mSOD1/ $\mathrm{BiP}^{+/-}$mice showed a numerical trend towards to be higher than in mSOD1 mice having normal expression of BiP (different probability levels compared to control genotypes; Figure 3A,B). The analysis of morphological characteristics of Iba-1-positive cells revealed a higher presence of activated cells, characterized by reduced length in branches $(\mathrm{F}(3,27)=77.9, p<0.0001)$ and elevated cell body area $(\mathrm{F}(3,27)=143.3, p<0.0001$ and their ratio with branches length $(\mathrm{F}(3,27)=52.03, p<0.0001)$, in $\mathrm{mSOD} 1 / \mathrm{BiP}^{+/}-$mice compared to mSOD1 animals with normal BiP expression, with the activated cells being residual in wildtype genotypes (Figure 4A,B). 


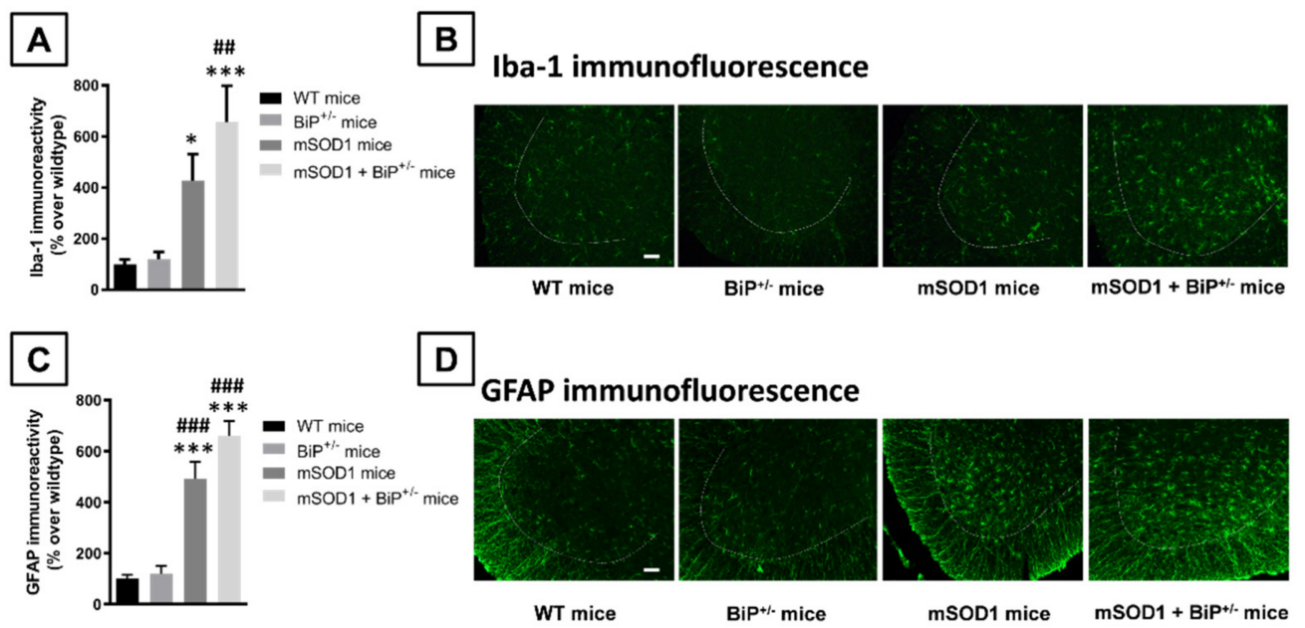

Figure 3. Quantification of Iba-1 (panel (A)) and GFAP (panel (C)) immunoreactivity, including representative images (panel (B) and (D), respectively; scale bar $=100 \mu \mathrm{m}$ ), in the lumbar ventral horn (marked with a dotted line) of the spinal cord in mSOD1 transgenic and wild-type male mice with normal or partial ablation of the BiP protein. Values are means \pm SEM of 5-7 animals per group. Data were assessed by one-way analysis of variance followed by the Tukey test $\left(^{*} p<0.05\right.$, *** $p<0.005$ versus WT mice; ${ }^{\# \#} p<0.01,{ }^{\# \#} p<0.005$ vs. $\mathrm{BiP}^{+/-}$mice).
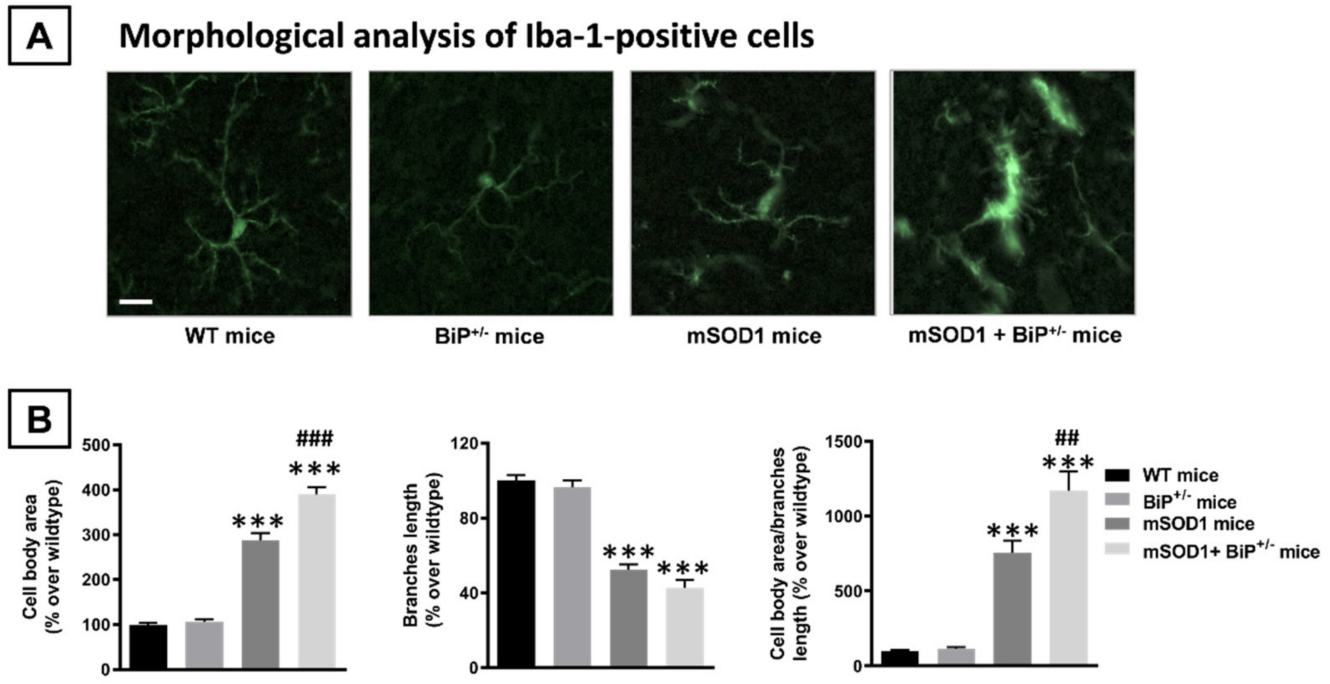

Figure 4. Representative images of Iba-1-positive cells (panel (A); scale bar $=25 \mu \mathrm{m}$ ) detected in the spinal cord (lumbar ventral horn) of mSOD1 transgenic and wild-type male mice with normal or partial ablation of the BiP protein, and their morphological analysis (cell body area, length of branches and their ratio; panel (B)). Values are means \pm SEM of 5-7 animals per group. Data were assessed by one-way analysis of variance followed by the Tukey test ${ }^{* * *} p<0.005$ vs. WT and $\mathrm{BiP}^{+/-}$ mice; ${ }^{\# \#} p<0.01,{ }^{\# \#} p<0.005$ vs. mSOD1 mice).

Similar results were also found for astroglial reactivity as measured with GFAP immunostaining $(\mathrm{F}(3,30)=28.85, p<0.0001$; Figure $3 \mathrm{C}, \mathrm{D})$, which also tended to be higher in $\mathrm{mSOD} 1 / \mathrm{BiP}^{+/-}$mice compared to the elevation found in mSOD1 mice, although the probability levels ( $p$ values) with respect to corresponding control genotypes were similar in both cases. Again, the analysis of morphological characteristics of GFAP-positive cells also revealed a higher presence of activated cells, characterized by elevated cell body area $(\mathrm{F}(3,29)=65.25, p<0.0001)$ and their ratio with branches length $(\mathrm{F}(3,29)=71.13, p<0.0001)$, in $\mathrm{mSOD} 1 / \mathrm{BiP}^{+/-}$mice compared to mSOD1 animals with normal BiP expression, with the activated cells being residual in wildtype genotypes (Figure 5A,B). 
A Morphological analysis of GFAP-positive cells

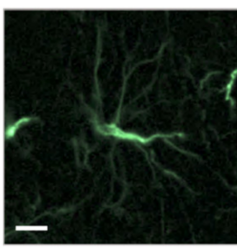

WT mice

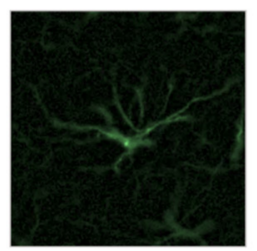

$\mathrm{BiP}^{+/-}$mice

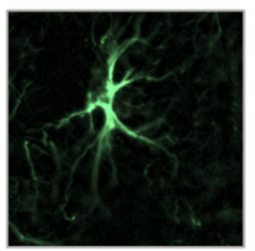

mSOD1 mice

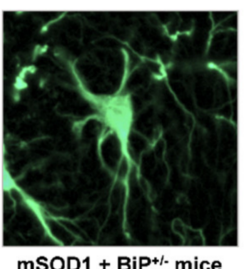

mSOD1 + BiP+l- mice
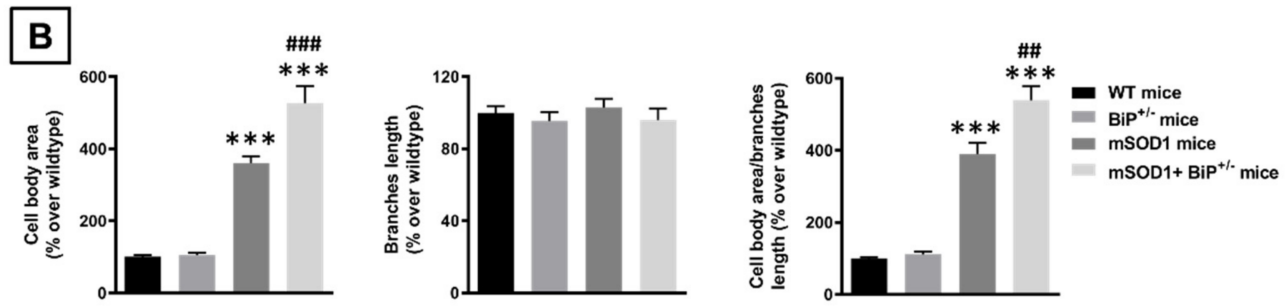

Figure 5. Representative images of GFAP-positive cells (panel (A); scale bar $=25 \mu \mathrm{m}$ ) detected in the spinal cord (lumbar ventral horn) of mSOD1 transgenic and wild-type male mice with normal or partial ablation of the BiP protein, and their morphological analysis (cell body area, length of branches and their ratio; panel (B)). Values are means \pm SEM of 5-7 animals per group. Data were assessed by one-way analysis of variance followed by the Tukey test ${ }^{* * *} p<0.005$ vs. WT and $\mathrm{BiP}^{+/-}$ mice; ${ }^{\# \#} p<0.01,{ }^{\# \# \#} p<0.005$ vs. mSOD1 mice).

Given the recently demonstrated interaction of BiP protein with the $\mathrm{CB}_{1}$ receptor [22], we also wanted to analyze the gene expression and protein levels of this receptor in the spinal cord in the four experimental groups. Whereas we found no differences in mRNA levels (Figure 6B), our data obtained with western blotting demonstrated significantly lower levels found in $\mathrm{mSOD} 1 / \mathrm{BiP}^{+/-}$mice compared to mSOD1 mice (Figure 6A).

\section{A}

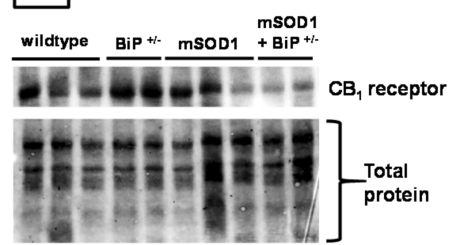

B

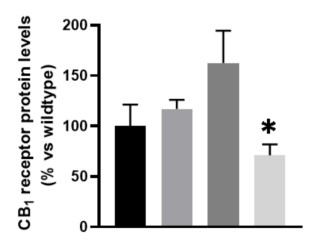

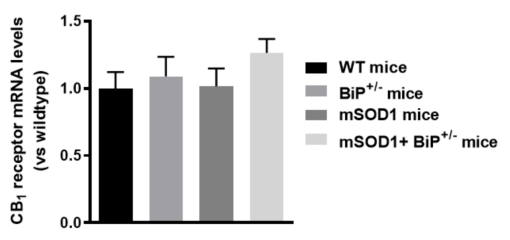

Figure 6. $\mathrm{CB}_{1}$ receptor protein (panel (A)) and mRNA (panel (B)) levels measured in the spinal cord of mSOD1 transgenic and wild-type male mice with normal or partial ablation of the BiP protein. Values are means \pm SEM of 5-7 animals per group. Data were assessed by one-way analysis of variance followed by the Tukey test ( ${ }^{*} p<0.05$ vs. mSOD1 mice).

\subsection{Studies in Experimental PD: Unilateral 6-OHDA Lesions in Wildtype and BiP ${ }^{+/-}$Mice}

The next objective of our study was to determine whether similar effects to those found upon BiP heterozigosity in experimental ALS translate to other neurodegenerative disorder, such as $\mathrm{PD}$, in which the activation of the $\mathrm{CB}_{1}$ receptor is also neuroprotective [15-17]. To this end, $\mathrm{BiP}^{+/-}$mice were unilaterally lesioned with the Parkinsonian neurotoxin 6OHDA with the purpose of confirming a possible greater neurotoxin susceptibility in these mice compared to wildtype animals. Our data, however, did not support that this was the case, as the behavioral and histopathological alterations caused by 6-OHDA were of similar magnitude in $\mathrm{BiP}^{+/-}$mice compared with wildtype animals. Thus, we first analyzed the animal response in the pole test, which resulted to be elevated by the lesion $(F(1,30)=5.994, p<0.05)$, but showing the same extent for both genotypes $(F(1,30)=0.0003$, ns; 2-way interaction: $F(1,30)=0.24$, ns; Figure 7A). The same situation was evident for the cylinder rearing test, which proved the expected increase in the hemiparesis shown by 
lesioned animals $(\mathrm{F}(1,30)=34.43, p<0.0001)$, but again at the same extent in both genotypes $(F(1,30)=0.77$, ns; 2-way interaction: $F(1,30)=0.20$, ns; Figure 7B).
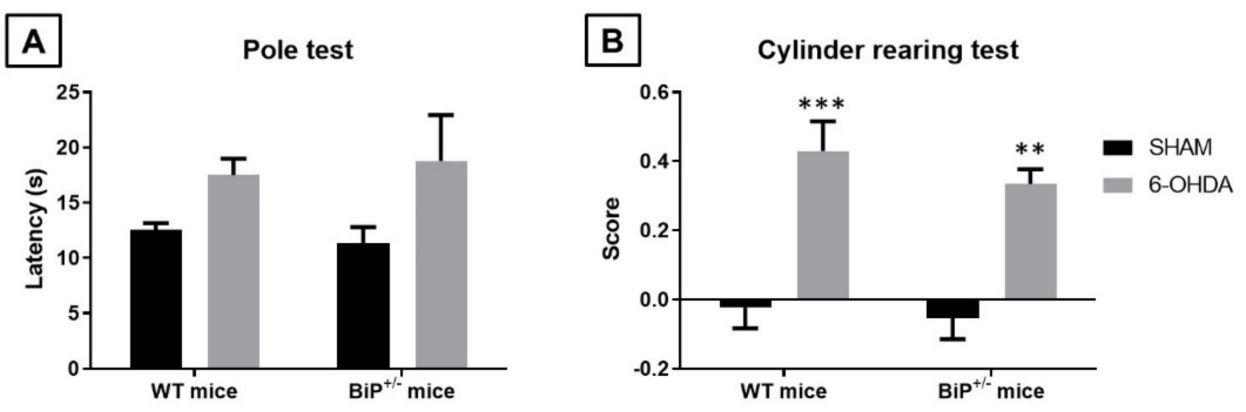

Figure 7. Response in the pole test (panel (A)) and in the cylinder rearing test (panel (B)) of wild-type male mice with normal or partial ablation of the BiP protein subjected to unilateral 6-OHDA lesions or sham-operated. Values are means \pm SEM of more than 5 animals per group. Data were assessed by two-way ANOVA followed by the Bonferroni test ${ }^{* *} p<0.01{ }^{* * *} p<0.005$ vs. the corresponding sham-operated group).

The lack of differences in the motor defects exhibited by both genotypes after the 6-OHDA lesion correlated with their reduction in tyrosine hydroxylase immunoreactivity in the substantia nigra in the lesioned side (compared to the contralateral nonlesioned side; $\mathrm{F}(1,30)=312.9, p<0.0001$ ), which resulted to be similar in both genotypes $(\mathrm{F}(1,30)=2.01$, ns; 2-way interaction: $\mathrm{F}(1,30)=0.35$, ns; Figure $8 \mathrm{~A})$. Similar results were obtained for the microglial reactivity (measured in this case with CD68 immunostaining) caused by 6-OHDA in the substantia nigra $(\mathrm{F}(1,30)=88.17, p<0.0001)$, which again reacted equally in both genotypes $(\mathrm{F}(1,30)=0.07$, ns; 2-way interaction: $\mathrm{F}(1,30)=0.05$, ns; Figure $8 \mathrm{~B}$ ), and also for the elevation of GFAP immunoreactivity, which reflects astrogliosis $(\mathrm{F}(1,30)=204.8, p<0.0001)$, once again with no observable differences across genotypes $(F(1,30)=0.16$, ns; 2-way interaction: $F(1,30)=0.002$, ns; Figure $8 C)$.
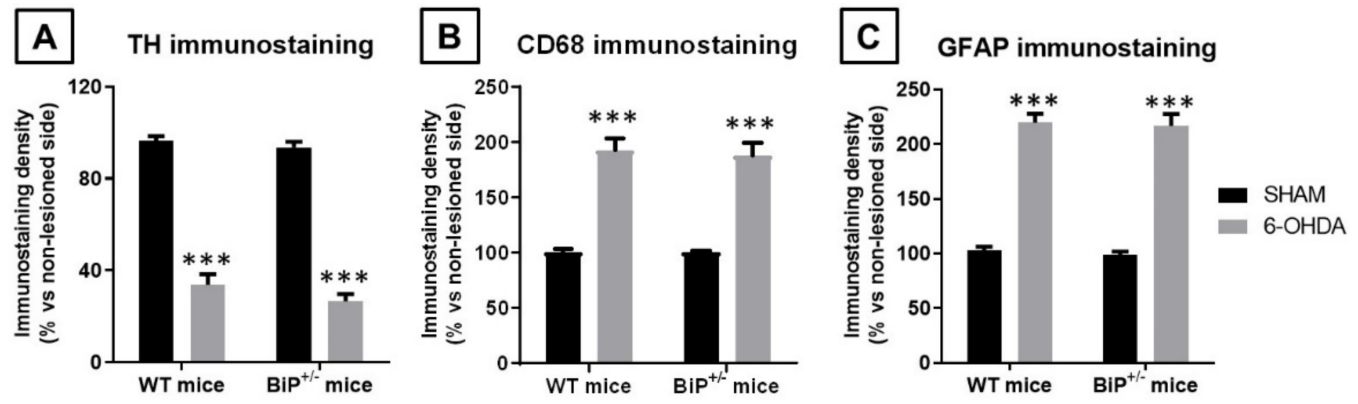

Figure 8. Immunoreactivity for TH (panel (A)), CD68 (panel (B)) and GFAP (panel (C)) measured in a selected area of the substantia nigra pars compacta of wild-type male mice with normal or partial ablation of the BiP protein subjected to unilateral 6-OHDA lesions or sham-operated. Values correspond to $\%$ of the ipsilateral lesioned side vs. contralateral non-lesioned side and were expressed as means \pm SEM of more than 5 animals per group. Data were assessed by two-way ANOVA followed by the Bonferroni test (*** $p<0.005$ vs. the corresponding sham-operated group).

\section{Discussion}

Our general objective in this study was to investigate the consequences of a heterozygous deficiency of the $\mathrm{BiP}$ protein, which, by potentially acting as an interacting protein, has been recently associated with $\mathrm{CB}_{1}$ receptor function [22], in two neurodegenerative disorders in which the activation of this receptor is known to be neuroprotective: ALS [18-20] and PD [15-17]. To this end, we used an experimental approach consisting on inducing experimental ALS or PD in mice having a partial deletion in the $\mathrm{BiP}$ gene and their 
corresponding wildtype littermates, and recording the development of the pathological phenotype to determine whether BiP-deficient mice were more vulnerable or not to these experimental insults. Our data showed that the response was different in ALS (greater vulnerability) compared to PD (no differences), which may indicate differences in the role played by $\mathrm{BiP}$ in relation with its canonical functions (i.e., control of protein folding and assembly, endoplasmic reticulum stress response) and, eventually, with $\mathrm{CB}_{1}$ receptor signaling in those neuronal subpopulations present in the CNS structures affected in both disorders.

In the case of ALS, our experimental approach consisted on generating a double mutant mouse model having the partial deficiency in BiP protein and the G93A mutant form found in the human SOD1 gene, whose behavioral and histopathological abnormalities were compared first with mSOD1 mice and also with the two control genotypes (wildtype or $\mathrm{BiP}^{+/-}$mice). Our data reveled a clear worsening in the neurological decline, as well as in the behavioral responses in specific motor tests, in particular, the rotarod test, in the double mutants, fueling our hypothesis that dysregulation or deficiency in BiP protein may affect the endogenous protective role exerted by the $\mathrm{CB}_{1}$ receptor as activated by the endogenous cannabinoid tone, then promoting a faster neurological decline in the double mutants. Our histopathological data obtained once animals were euthanized at the age showing the maximal neurological deterioration revealed that this was accompanied by higher levels of glial reactivity and acquisition of an activated phenotype, in particular in microglial cells but also in astrocytes, in the ventral horn of the spinal cord at lumbar levels. However, we could not demonstrate that such greater reactive gliosis was associated with also a greater extent in the loss of motor neurons in the spinal cord at the age at which animals were euthanized. It is possible that this response may take place at later phases in parallel to a worsening in the neurological decline, but this will remain to be investigated in further studies. Additionally, pending of future studies is testing that the faster progression found in the pathological phenotype in double mutants is a consequence of the loss of $C_{1}$ receptor-mediated neuroprotective effects linked in ALS with BiP function as interacting protein. It is important to remark that this protein interacts with many other cellular proteins and that its dysregulation has been already associated with ALS pathogenesis by mechanisms that a priori do not involve the participation of the $\mathrm{CB}_{1}$ receptor [23-25], so the issue will require additional research that may test a cause-effect relationship between dysregulation in $\mathrm{BiP}$ function and loss of $\mathrm{CB}_{1}$-mediated neuroprotective effects, and vice versa. We can anticipate here that $\mathrm{CB}_{1}$ receptor gene expression resulted to be similar in the spinal cord of wildtype or mSOD1 mice with normal or partial ablation of BiP protein, but this result was relatively expected as the recent data indicate that BiP serves as an interacting protein for the $\mathrm{CB}_{1}$ receptor [22], so the defects in this protein should affect primarily the signaling for this receptor rather than its gene expression. In fact, the analysis of protein levels for the $\mathrm{CB}_{1}$ receptor proved lower levels in the double mutants compared to mSOD1 mice, which may be associated with these defects in receptor signaling, although this will require additional research.

The results were different in the case of $\mathrm{PD}$, the other disorder investigated in this study. In this case, we followed a different experimental strategy, using unilateral 6-OHDA striatal lesions in both $\mathrm{BiP}^{+/-}$and wildtype mice and quantifying the consequences of this lesion at behavioral and histopathological levels. We were unable to detect any differences in the response of animals having a partial deficiency in BiP protein with respect to their controls in two classic parkinsonian motor tests, and the same happened with the analysis of the lesioned substantia nigra in relation with the status of tyrosine hydroxylase-positive neurons and the glial reactivity. Such observation contrasts with previous studies that situated BiP as a neuroprotectant factor in PD acting through mechanisms that involve UPR pathways [27], but these studies were conducted in PD models based on the formation of $\alpha$-synuclein aggregates, which is not the case with 6-OHDA lesions. This may be an important difference in relation with the ALS model based on mSOD1 (as well as additional models based on the RNA-binding protein TDP-43), which form protein aggregates then 
facilitating the involvement of BiP [28]. It is also possible that the differences in BiP involvement between PD and ALS may be related to the proposed role of this protein as an interacting protein for $\mathrm{CB}_{1}$ receptors, which may be different in those neuronal subpopulations affected in PD with respect to those affected in ALS, a fact that would also require further investigation.

\section{Materials and Methods}

\subsection{Animals, Experiments and Sampling}

Experiments were conducted with two mouse colonies: (i) B6SJL-Tg(SOD1*G93A)1Gur/J transgenic (mSOD1 mice) and non-transgenic littermate sibling mice bred in our animal facilities from initial breeders provided by Dr. Rosario Osta (LagenBio-Ingen, University of Zaragoza, Spain), and (ii) B6.129(Cg)-Hspa $5^{\mathrm{tm} 1.1 \mathrm{Alee} / \mathrm{J}}$ mice (BiP ${ }^{+/-}$mice) purchased to Jackson Laboratories (Bar Harbor, ME, USA). Both colonies were housed in a room with controlled photoperiod (08:00-20:00 light) and temperature $\left(22 \pm 1{ }^{\circ} \mathrm{C}\right)$ with free access to standard diet and water. All animal experiments were conducted according to local and European rules (directive 2010/63/EU), as well as conformed to ARRIVE guidelines. They were approved by the ethical committees of our university and the regulatory institution (ref. PROEX 059/16).

In a first experiment, mutant SOD1(G93A) transgenic mice were mated with $\mathrm{BiP}^{+/-}$ mice (Note that these two mouse colonies were in different backgrounds, so to avoid that this may affect the experiment, only F1 littermates were analyzed) to generate four genotypes to be investigated: (i) wildtype mice with normal expression of the BiP protein (referred to as WT mice); (ii) wildtype mice with heterozygous deletion of the BiP protein (referred to as $\mathrm{BiP}^{+/-}$mice); (iii) mSOD1(G93A) transgenic mice with normal expression of the BiP protein (referred to as mSOD1 mice); and (iv) mSOD1(G93A) transgenic mice with partial genetic ablation of the $\mathrm{BiP}$ protein (referred to as $\mathrm{mSOD} 1 / \mathrm{BiP}^{+/-}$mice). All male mice generated were genotyped for the presence or absence of the transgene containing the SOD1 ${ }^{\mathrm{G} 93 \mathrm{~A}}$ mutation (protocol provided by LagenBio-Ingen), and the presence or partial absence of BIP expression (protocol provided by Jackson Laboratories), and were assigned to the four groups according to their genotype. When animals reached 9 weeks of age (at this age mSOD1 mice are still presymptomatic or early symptomatic [29]), they were weekly $(9,10$, and 11 weeks) weighted and subjected to three different behavioral analyses (neurological score, performance in the rotarod and the hanging wire tests) designed to record the progression of their pathological phenotype at the neurological level. Afterwards, all animals in the four genotypes were euthanized by rapid decapitation and their spinal cords were rapidly removed. The spinal samples (lumbar area) to be used for histology were fixed for one day at $4{ }^{\circ} \mathrm{C}$ in fresh $4 \%$ paraformaldehyde prepared in $0.1 \mathrm{M}$ phosphate buffered-saline (PBS), pH 7.4. Samples were cryoprotected by immersion in a $30 \%$ sucrose solution for a further day, and finally stored at $-80^{\circ} \mathrm{C}$ for Nissl staining and immunohistochemical analysis. The spinal samples (also lumbar area) to be used for biochemistry were rapidly frozen by immersion in cold 2-methylbutane, and stored at -80 ${ }^{\circ} \mathrm{C}$ for qPCR or western blot analysis. In a separate study, mice of the two above mSOD1 genotypes $\left(\mathrm{BiP}^{+/+}\right.$or $\left.\mathrm{BiP}^{+/-}\right)$were used to determine their differences in animal survival, using the following criteria to trigger euthanasia: (i) severe weight loss (>25\%); (ii) animals having bristly hair, closed eyes, lethargy or immobility; (iii) paralysis in both hind limbs; and (iv) inability to walk and lack of response to manipulation.

In a second experiment, male C57BL/ 6 wildtype and $\mathrm{BIP}^{+/-}$mice were used at adult age (3-4-month-old; 25-30 g weight) for stereotaxic unilateral application of 6-OHDA or saline [30]. To do that, mice were anaesthetized (ketamine $40 \mathrm{mg} / \mathrm{kg}+$ xylazine $4 \mathrm{mg} / \mathrm{kg}$, i.p.) $30 \mathrm{~min}$ after pretreatment with desipramine $(25 \mathrm{mg} / \mathrm{kg}$, i.p.), and then 6-OHDA free base ( $2 \mu \mathrm{L}$ at a concentration of $2 \mu \mathrm{g} / \mu \mathrm{L}$ saline in $0.2 \%$ ascorbate to avoid oxidation) or saline (for control mice) were injected stereotaxically into the right striatum at a rate of $0.5 \mu \mathrm{L} / \mathrm{min}$, using the following coordinates: $+0.4 \mathrm{~mm} \mathrm{AP}, \pm 1.8 \mathrm{~mm} \mathrm{ML}$ and $-3.5 \mathrm{~mm}$ DV, as described in [31]. Once injected, the needle was left in place for $5 \mathrm{~min}$ before 
being slowly withdrawn, thus avoiding reflux and a rapid increase in intracranial pressure. Control animals were sham-operated and injected with $2 \mu \mathrm{L}$ of saline using the same coordinates. The lesions were generated using unilateral injection, the advantage of which is that contralateral structures serve as controls for the different analyses. Two weeks after the 6-OHDA lesion or the sham-operation, all animals were analyzed in the pole test and the cylinder rearing test, at the end of which animals were killed by rapid and careful decapitation and their brains were rapidly removed. Brains were fixed for one day at $4{ }^{\circ} \mathrm{C}$ in fresh $4 \%$ paraformaldehyde prepared in $0.1 \mathrm{M}$ PBS, pH 7.4. Samples were cryoprotected by immersion in a $30 \%$ sucrose solution for a further day, and finally stored at $-80{ }^{\circ} \mathrm{C}$ for immunohistochemical analysis in the substantia nigra.

\subsection{Behavioral Recording}

Neurological score. Mice were evaluated for neurological decline using a numerical scale published previously [29] with modifications. The scale ranged from 0 to 15 distributed in three sub-scales (0-5) concentrated on ambulation, strength analysis and hind-foot reflex test. A final score $=0$ corresponds to animals which are not symptomatic, whereas a score $=15$ reflects a state of total functional loss in hindlimbs and postural control. The assessment of ambulation was carried out placing the animal inside a corridor $(10 \times 10 \times$ $80 \mathrm{~cm}$ ), while evaluating postural control and the way in which hindlimbs were leaned during motion. The strength test evaluated the animal ability to drag and offer resistance when the tail was pulled softly to the opposite direction in which the animal moves. Lastly, the hind-foot reflex test evaluated the stiffness of the limbs and their coordination when the mouse was suspended by the tail $10 \mathrm{~cm}$ over the surface. The final score was calculated from the sum of values reached in each sub-scale.

Rotarod test. Mice were evaluated for possible motor weakness using the rotarod test, using a LE8200 device (Panlab, Barcelona, Spain). Mice were exposed to a period of acclimation and training (first session: 0 r.p.m. for 30 s; second and third sessions: 4 r.p.m. for $60 \mathrm{~s}$, with periods of $10 \mathrm{~min}$ between sessions), followed $30 \mathrm{~min}$ later by the assay. Mice were placed into the apparatus and the rotational speed was increased from 4 to 40 r.p.m. over a period of $300 \mathrm{~s}$ to measure the time to fall off. Mice were tested for 3 consecutive trials with a rest period of approximately $15 \mathrm{~min}$ between trials and the mean of the 3 trials was calculated.

Hanging wire test. The latency of mice to fall from a wire cage top, which was slowly inverted and suspended at approximately $30 \mathrm{~cm}$ to the floor, was also used as an index of motor weakness. The test was repeated three times to obtain the mean value of the three trials.

Pole test. Mice were placed head-upward on the top of a vertical rough-surfaced pole (diameter $8 \mathrm{~mm}$; height $55 \mathrm{~cm}$ ) and the time until animals descended to the floor was recorded with a maximum duration of $120 \mathrm{~s}$. When the mouse was not able to turn downward and instead dropped from the pole, the time was taken as $120 \mathrm{~s}$ (default value).

Cylinder rearing test. Given that the lesion was unilateral in the experiment with 6-OHDA, this test attempted to quantify the degree of forepaw (ipsilateral, contralateral, or both) preference for wall contacts after placing the mouse in a methacrylate transparent cylinder (diameter: $15.5 \mathrm{~cm}$; height: $12.7 \mathrm{~cm}$; [32]. Each score was made out of a 3 min trial with a minimum of 4 wall contacts.

\subsection{Histological Procedures}

Tissue slicing. In the ALS experiment, fixed spinal cords were sliced with a cryostat at the lumbar level (L4-L6) to obtain coronal sections ( $20 \mu \mathrm{m}$ thick) that were collected on gelatin-coated slides. Sections were used for procedures of Nissl-staining and immunofluorescence. In the PD experiment, brains were sliced in coronal sections (containing the substantia nigra) in a cryostat ( $30 \mu \mathrm{m}$ thick) and collected on antifreeze solution (glycerol/ethylene glycol/PBS; 2:3:5) and stored at $-20^{\circ} \mathrm{C}$ until used. Sections were mounted on gelatin-coated slides. 
Nissl staining. Slices were used for Nissl staining using cresyl violet, as previously described [33], which permitted to determine the effects of particular treatments on cell number. A Leica DMRB microscope (Leica, Wetzlar, Germany) and a DFC300Fx camera (Leica) were used to study and photograph the tissue, respectively. To count the number of Nissl-stained motor neurons $\left(>400 \mu \mathrm{m}^{2}\right)$ in the ventral horn, high-resolution photomicrographs were taken with a $10 \times$ objective under the same conditions of light, brightness, and contrast. Counting was carried out with ImageJ software (U.S. National Institutes of Health, Bethesda, MD, USA, http://imagej.nih.gov/ij/, 1997-2012). At least 6 images per animal were analyzed to establish the mean of all animals studied in each group. Analyses were always conducted by experimenters who were blinded to all animal characteristics. Data were expressed as arbitrary units.

Immunofluorescence analysis in the ALS experiment. Spinal slices were used for detection and quantification of GFAP or Iba- 1 immunofluorescence. After preincubation for $1 \mathrm{~h}$ with Tris-buffered saline with $0.1 \%$ Triton X-100 (pH 7.5), sections were sequentially incubated overnight at $4{ }^{\circ} \mathrm{C}$ with the following polyclonal antibodies: (i) anti-Iba-1 (Wako Chemicals, Richmond, VI, USA) used at 1:500; or (ii) anti-GFAP (Dako Cytomation, Glostrup, Denmark) used at 1:200, followed by washing in Tris-buffered saline and a new incubation (at $37^{\circ} \mathrm{C}$ for $2 \mathrm{~h}$ ) with an anti-rabbit secondary antibody conjugated with Alexa 488 (Invitrogen, Carlsbad, CA, USA). A DMRB microscope and a DFC300Fx camera (Leica, Wetzlar, Germany) were used for slide observation and photography. The mean density of immunolabelling was measured in the selected areas using at least 6 sections per animal. In all analyses, data were transformed to the percentage over the mean obtained in the wild-type group for each parameter. For quantification of the glial activation state, we classified GFAP- or Iba-1-positive cells in resting or activated based on morphological criteria published previously [34], which consist in calculating the ratio between cell body area and cell process length.

Immunostaining analysis in the PD experiment. Brain sections containing the substantia nigra were mounted on gelatin-coated slides, and, once adhered, washed in $0.1 \mathrm{M}$ potassium PBS (KPBS) at pH 7.4. Endogenous peroxidase was blocked by $30 \mathrm{~min}$ incubation at room temperature in peroxidase blocking solution (Dako Cytomation, Glostrup, Denmark). After several washes with KPBS, sections were incubated overnight at room temperature with the following polyclonal antibodies: (i) rabbit anti-TH (Chemicon-Millipore, Temecula, CA, USA) used at 1/200; (ii) rat anti-mouse CD68 antibody (AbD Serotec, Oxford, UK) used at 1/200; or (iii) rabbit anti-mouse GFAP antibody (Dako Cytomation, Glostrup, Denmark) used at $1 / 200$. Dilutions were carried out in KPBS containing $2 \%$ bovine serum albumin and 0.1\% Triton X-100 (Sigma Chem., Madrid, Spain). After incubation, sections were washed in KPBS, followed by incubation with the corresponding biotinylated secondary antibody (1/200) (Vector Laboratories, Burlingame, CA, USA) for $1 \mathrm{~h}$ at room temperature. An avidin-biotin complex (Vector Laboratories, Burlingame, CA, USA) and 3,3'-diaminobenzidine substrate-chromogen system (Dako Cytomation, Glostrup, Denmark) were used to obtain a visible reaction product. Negative control sections were obtained using the same protocol with omission of the primary antibody. A Leica DMRB microscope and a DFC300FX camera (Leica, Wetzlar, Germany) were used for the observation and photography of the slides, respectively. For quantification of $\mathrm{TH}$, GFAP or CD68 immunostaining in the substantia nigra, we used the NIH Image Processing and Analysis software (ImageJ; NIH, Bethesda, MD, USA) using 4-5 sections, separated approximately by $200 \mu \mathrm{m}$, and observed with $5 \times-20 \times$ objectives depending on the method and the brain area under quantification. In all sections (a minimum of $6 \mathrm{per}$ animal were used), the same area of the substantia nigra pars compacta were analyzed. Analyses were always conducted by experimenters who were blinded to all animal characteristics. Data were expressed as percentage of immunostaining intensity in the ipsilateral (lesioned) side over the contralateral (non-lesioned) side. 


\subsection{Real Time RT-qPCR Analysis}

Total RNA was extracted from tissues using Trizol (Life Technologies, Alcobendas, Spain). The total amount of RNA extracted was quantified by spectrometry at $260 \mathrm{~nm}$ and its purity was calculated as the ratio between the absorbance values at 260 and $280 \mathrm{~nm}$. RNA integrity was confirmed in agarose gels. DNA was removed and single-stranded complementary DNA was synthesized from $0.8 \mu \mathrm{g}$ of total RNA using a commercial kit (Rneasy Mini Quantitect Reverse Transcription, Qiagen, Izasa, Madrid, Spain). The reaction mixture was kept frozen at $-20{ }^{\circ} \mathrm{C}$ until enzymatic amplification. Quantitative real-time PCR assays were performed using TaqMan Gene Expression Assays (Applied Biosystems, Foster City, CA, USA) to quantify mRNA levels for $\mathrm{CB}_{1}$ receptor (Mm00432621_s1), using GAPDH expression (Mm99999915_g1) as an endogenous control gene for normalization. The PCR assay was performed using the 7300 Fast Real-Time PCR System (Applied Biosystems, Foster City, CA, USA) and the threshold cycle (Ct) was calculated by the instrument's software (7300 Fast System, Applied Biosystems, Foster City, CA, USA). Expression levels were calculated using the $2^{-\Delta \Delta \mathrm{Ct}}$ method, but, for presentation, data were transformed to the percentage over the mean obtained in the wild-type group for each parameter.

\subsection{Western Blot Analysis}

Frozen tissues were homogenized in an ice-cold radioimmunoprecipitation assay (RIPA) buffer for protein extraction. Homogenates were centrifuged at $10,000 \times g$ for 15 min at $4{ }^{\circ} \mathrm{C}$. Bio-Rad DC protein assay kit (Bio-Rad Laboratories, CA, USA) was used to quantify protein concentration, using bovine serum albumin (BSA) as the standard protein. Then, $15 \mu \mathrm{g}$ of protein were boiled for $5 \mathrm{~min}$ in Laemmli SDS loading buffer (10\% glycerol, 5\% SDS, 5\% $\beta$-mercaptoethanol, $0.01 \%$ bromophenol blue, and $125 \mathrm{mM}$ TRIS-HCl, pH 6.8) and loaded onto a $12 \%$ acrylamide gel (TGX Stain-free Gel FastCast; Bio-Rad Laboratories, CA, USA). After electrophoresis, proteins were transferred to PVDF membranes (Immobilon-P, Millipore, MA, USA) using mini Trans-Blot Electrophoretic transfer cell (Bio-Rad Laboratories, CA, USA). Membranes were then blocked for $1 \mathrm{~h}$ at room temperature with Tris-buffered saline containing 5\% BSA and $0.1 \%$ Tween-20, and incubated overnight at $4{ }^{\circ} \mathrm{C}$ with the anti-CB1 polyclonal antibody (CB1-Rb-Af380, Frontier Institute, Hokkaido, Japan) used at $1 / 10,000$. Membranes were finally incubated with an ECL horseradish peroxidase-linked whole secondary antibody (GE Healthcare UK Limited, Buckinghamshire, UK) used at a 1/10,000 dilution for $1 \mathrm{~h}$ at room temperature. Reactive bands were detected by chemiluminescence with the Amersham ECL Prime Western Blotting Detection Reagent (GE Healthcare UK Limited, Buckinghamshire, UK). Images were analyzed with Image Lab software (Bio-Rad Laboratories, CA, USA). Data were calculated as the ratio between the optical densities of the specific protein band and the total protein measured in membranes, and then normalized as percentages over the values of wild-type mice.

\subsection{Statistics}

Data were assessed using one-way or two-way ANOVA (with repeated measures, if required) followed by the Tukey or the Bonferroni test, as required, using GraphPad Prism, version 8.00 for Windows (GraphPad Software, San Diego, CA, USA). Survival data were assessed using Log-Rank test and presented with a Kaplan-Meier analysis. A p value lower than 0.05 was used as the limit for statistical significance. The sample sizes in the different experimental groups were always $\geq 5$.

\section{Conclusions}

Therefore, our data suggest that a dysregulation in BiP protein may possibly contribute to ALS pathogenesis, but this did not occur in experimental PD, or at least not in the model of PD used in this study. The hypothesis derived from both paradigms is that the neuroprotective effects associated with the activation of the $\mathrm{CB}_{1}$ receptor in experimental ALS [18-20], but not those found in experimental PD [15-17], might be modulated by BiP 
function, a notion that will require additional research. Preliminary data obtained here may anticipate that this is the case in ALS, as $C_{1}$ receptor levels were found to be significantly reduced in $\mathrm{mSOD} 1$ mice having partial deletion of $\mathrm{BiP}$ gene.

Author Contributions: Funding acquisition (M.G. and J.F.-R.); Study design, coordination and supervision (J.F.-R., M.G. and I.R.-C.); Development of the colony of $\mathrm{BiP}^{+/-}$mice (C.C.-I.); Studies in mSOD1 transgenic mice: design and methodology (M.G.-A., C.R.-C., I.S.-G. and E.d.L.); Studies in 6-OHDA-lesioned mice: design and methodology (S.B. and C.G.); Statistical analysis of the data (M.G.-A., C.R.-C., S.B. and J.F.-R.); Manuscript preparation (J.F.-R. with the revision and approval of all authors). All authors have read and agreed to the published version of the manuscript.

Funding: This work has been supported by grants from CIBERNED (CB06/05/0089, CB06/05/0005 and PI2018/01-1), MICIU (RTI-2018-098885-B-100 and RTI-2018-095311-B-100), and ELA-Madrid-CM (B2017/BMD-3813). These agencies had no further role in study design, the collection, analysis and interpretation of data, in the writing of the report, or in the decision to submit the paper for publication.

Institutional Review Board Statement: All experiments were conducted according to European guidelines (directive 2010/63/EU) and approved by the "Comité de Experimentación Animal" of our university (ref. PROEX 059/16).

Informed Consent Statement: Not applicable.

Data Availability Statement: Data supporting reported results may be supplied upon request by authors.

Acknowledgments: Marta Gómez-Almería, Carlos Costas-Insua and Sonia Burgaz are predoctoral fellows supported by the FPI Programme-MICIU, FPU Programme, and UCM-Predoctoral Programme, respectively.

Conflicts of Interest: The authors declare no conflict of interest.

\section{References}

1. Fernández-Ruiz, J. The biomedical challenge of neurodegenerative disorders: An opportunity for cannabinoid-based ther-apies to improve on the poor current therapeutic outcomes. Br. J. Pharmacol. 2019, 176, 1370-1383. [CrossRef] [PubMed]

2. Fernández-Ruiz, J.; Moro, M.A.; Martinez-Orgado, J. Cannabinoids in Neurodegenerative Disorders and Stroke/Brain Trauma: From Preclinical Models to Clinical Applications. Neurotherapeutics 2015, 12, 793-806. [CrossRef]

3. Aymerich, M.S.; Aso, E.; Abellanas, M.A.; Tolon, R.M.; Ramos, J.A.; Ferrer, I.; Romero, J.; Fernández-Ruiz, J. Cannabinoid pharma-cology/therapeutics in chronic degenerative disorders affecting the central nervous system. Biochem. Pharmacol. 2018, 157, 67-84. [CrossRef]

4. Chiarlone, A.; Bellocchio, L.; Blázquez, C.; Resel, E.; Soria-Gómez, E.; Cannich, A.; Ferrero, J.J.; Sagredo, O.; Benito, C.; Romero, J.; et al. A restricted population of CB1 cannabinoid re-ceptors with neuroprotective activity. Proc. Natl. Acad. Sci. USA 2014, 111, 8257-8262. [CrossRef]

5. Hiebel, C.; Behl, C. The complex modulation of lysosomal degradation pathways by cannabinoid receptors 1 and 2. Life Sci. 2015, 138, 3-7. [CrossRef]

6. Aso, E.; Palomer, E.; Juvés, S.; Maldonado, R.; Muñoz, F.J.; Ferrer, I. CB1 Agonist ACEA Protects Neurons and Reduces the Cognitive Impairment of A $\beta$ PP/PS1 Mice. J. Alzheimer's Dis. 2012, 30, 439-459. [CrossRef] [PubMed]

7. Navarro, G.; Borroto-Escuela, D.; Angelats, E.; Etayo, Í.; Reyes-Resina, I.; Pulido-Salgado, M.; Rodríguez-Pérez, A.I.; Canela, E.I.; Saura, J.; Lanciego, J.L.; et al. Receptor-heteromer mediated regulation of endocan-nabinoid signaling in activated microglia. Role of CB1 and CB2 receptors and relevance for Alzheimer's disease and levo-dopa-induced dyskinesia. Brain Behav. Immun. 2018, 67, 139-151. [CrossRef]

8. Crunfli, F.; Vrechi, T.A.; Costa, A.P.; Torrão, A.S. Cannabinoid Receptor Type 1 Agonist ACEA Improves Cognitive Deficit on STZ-Induced Neurotoxicity through Apoptosis pathway and NO Modulation. Neurotox. Res. 2019, 35, 516-529. [CrossRef] [PubMed]

9. Blázquez, C.; Chiarlone, A.; Sagredo, O.; Aguado, T.; Pazos, M.R.; Resel, E.; Palazuelos, J.; Julien, B.; Salazar, M.; Börner, C.; et al. Loss of striatal type 1 cannabinoid receptors is a key pathogenic factor in Huntington's disease. Brain 2011, 134, 119-136. [CrossRef]

10. Blazquez, C.; Chiarlone, A.; Bellocchio, L.; Resel, E.; Pruunsild, P.; García-Rincón, D.; Sendtner, M.; Timmusk, T.; Lutz, B.; Galve-Roperh, I.; et al. The CB1 cannabinoid receptor signals striatal neuroprotection via a PI3K/Akt/mTORC1/BDNF pathway. Cell Death Differ. 2015, 22, 1618-1629. [CrossRef] 
11. Maya-López, M.; Colín-González, A.L.; Aguilera, G.; De Lima, M.E.; Colpo-Ceolin, A.; Rangel-Lopez, E.; Villeda-Hernández, J.; Rembao-Bojórquez, D.; Túnez, I.; Luna-López, A.; et al. Neuroprotective effect of WIN55,212-2 against 3-nitropropionic acid-induced toxicity in the rat brain: Involvement of CB1 and NMDA receptors. Am. J. Transl. Res. 2017, 9, $261-274$.

12. Ruiz-Calvo, A.; Maroto, I.B.; Bajo-Grañeras, R.; Chiarlone, A.; Gaudioso, A.; Ferrero, J.J.; Resel, E.; Sánchez-Prieto, J.; RodríguezNavarro, A.J.; Marsicano, G.; et al. Pathway-Specific Control of Striatal Neuron Vulnerability by Corticostriatal Cannabinoid CB1 Receptors. Cereb. Cortex 2018, 28, 307-322. [CrossRef]

13. Rossi, S.; Furlan, R.; De Chiara, V.; Muzio, L.; Musella, A.; Motta, C.; Studer, V.; Cavasinni, F.; Bernardi, G.; Martino, G.; et al. Cannabinoid CB1 receptors regulate neuronal TNF- $\alpha$ effects in experimental auto-immune encephalomyelitis. Brain Behav. Immun. 2011, 25, 1242-1248. [CrossRef]

14. Moreno-Martet, M.; Feliú, A.; Espejo-Porras, F.; Mecha, M.; Carrillo-Salinas, F.J.; Fernández-Ruiz, J.; Guaza, C.; de Lago, E. The disease-modifying effects of a Sativex-like combination of phytocannabinoids in mice with experimental autoimmune en-cephalomyelitis are preferentially due to $\Delta 9$-tetrahydrocannabinol acting through CB1 receptors. Mult. Scler. Relat. Disord. 2015, 4, 505-511. [CrossRef]

15. Chung, Y.C.; Bok, E.; Huh, S.H.; Park, J.Y.; Yoon, S.H.; Kim, S.R.; Kim, Y.S.; Maeng, S.; Park, S.H.; Jin, B.K. Cannabinoid receptor type 1 protects nigrostriatal dopaminergic neurons against MPTP neurotoxicity by inhibiting microglial activation. J. Immunol. 2011, 187, 6508-6517. [CrossRef] [PubMed]

16. Pérez-Rial, S.; García-Gutiérrez, M.S.; Molina, J.A.; Pérez-Nievas, B.G.; Ledent, C.; Leiva, C.; Leza, J.C.; Manzanares, J. Increased vulnerability to 6-hydroxydopamine lesion and reduced development of dyskinesias in mice lacking CB1 cannabinoid receptors. Neurobiol. Aging 2011, 32, 631-645. [CrossRef] [PubMed]

17. Martínez-Pinilla, E.; Aguinaga, D.; Navarro, G.; Rico, A.J.; Oyarzábal, J.; Sánchez-Arias, J.A.; Lanciego, J.L.; Franco, R. Targeting CB1 and GPR55 Endocannabinoid Receptors as a Potential Neuroprotective Approach for Parkinson's Disease. Mol. Neurobiol. 2019, 56, 5900-5910. [CrossRef]

18. Abood, M.E.; Rizvi, G.; Sallapudi, N.; McAllister, S.D. Activation of the CB1 cannabinoid receptor protects cultured mouse spinal neurons against excitotoxicity. Neurosci. Lett. 2001, 309, 197-201. [CrossRef]

19. Zhao, P.; Ignacio, S.; Beattie, E.C.; Abood, M.E. Altered presymptomatic AMPA and cannabinoid receptor trafficking in motor neurons of ALS model mice: Implications for excitotoxicity. Eur. J. Neurosci. 2008, 27, 572-579. [CrossRef] [PubMed]

20. Rossi, S.; De Chiara, V.; Musella, A.; Cozzolino, M.; Bernardi, G.; Maccarrone, M.; Mercuri, N.B.; Carrì, M.T.; Centonze, D. Abnormal sensitivity of cannabinoid CB1 receptors in the striatum of mice with experimental amyotrophic lateral sclerosis. Amyotroph. Lateral Scler. 2019, 11, 83-90. [CrossRef] [PubMed]

21. Oliver, E.E.; Hughes, E.K.; Puckett, M.K.; Chen, R.; Lowther, W.T.; Howlett, A.C. Cannabinoid Receptor Interacting Protein 1a (CRIP1a) in Health and Disease. Biomolecules 2020, 10, 1609. [CrossRef]

22. Costas-Insua, C.; Moreno, E.; Maroto, I.B.; Ruiz-Calvo, A.; Bajo-Grañeras, R.; Martín-Gutiérrez, D.; Diez-Alarcia, R.; Vilaró, M.T.; Cortés, R.; García-Font, N.; et al. Identification of BiP as a CB1 Receptor-Interacting Protein That Fine-Tunes Cannabinoid Signaling in the Mouse Brain. J. Neurosci. 2021, 41, 7924-7941. [CrossRef]

23. Gorbatyuk, M.; Gorbatyuk, O. Review: Retinal degeneration: Focus on the unfolded protein response. Mol. Vis. 2013, 19, 1985. [PubMed]

24. Casas, C. GRP78 at the Centre of the Stage in Cancer and Neuroprotection. Front. Neurosci. 2017, 11, 177. [CrossRef]

25. Jin, H.; Komita, M.; Aoe, T. The Role of BiP Retrieval by the KDEL Receptor in the Early Secretory Pathway and its Effect on Protein Quality Control and Neurodegeneration. Front. Mol. Neurosci. 2017, 10, 222. [CrossRef]

26. Luo, S.; Mao, C.; Lee, B.; Lee, A.S. GRP78/BiP is required for cell proliferation and protecting the inner cell mass from apoptosis during early mouse embryonic development. Mol. Cell Biol. 2006, 26, 5688-5697. [CrossRef] [PubMed]

27. Gorbatyuk, M.; Shabashvili, A.; Chen, W.; Meyers, C.; Sullivan, L.F.; Salganik, M.; Lin, J.H.; Lewin, A.; Muzyczka, N.; Gorbatyuk, O.S. Glucose Regulated Protein 78 Diminishes $\alpha$-Synuclein Neurotoxicity in a Rat Model of Parkinson Disease. Mol. Ther. 2012, 20, 1327-1337. [CrossRef] [PubMed]

28. Jeon, G.S.; Shim, Y.-M.; Lee, D.-Y.; Kim, J.-S.; Kang, M.; Ahn, S.H.; Shin, J.-Y.; Geum, D.; Hong, Y.-H.; Sung, J.-J. Pathological Modification of TDP-43 in Amyotrophic Lateral Sclerosis with SOD1 Mutations. Mol. Neurobiol. 2019, 56, 2007-2021. [CrossRef]

29. Cueto, C.R.; Santos-García, I.; García-Toscano, L.; Espejo-Porras, F.; Bellido, M.; Fernández-Ruiz, J.; Munoz, E.; de Lago, E. Neuroprotective effects of the cannabigerol quinone derivative VCE-003.2 in SOD1G93A transgenic mice, an experimental model of amyotrophic lateral sclerosis. Biochem. Pharmacol. 2018, 157, 217-226. [CrossRef]

30. García, C.; Palomo-Garo, C.; García-Arencibia, M.; Ramos, J.; Pertwee, R.; Fernández-Ruiz, J. Symptom-relieving and neuroprotective effects of the phytocannabinoid $\Delta^{9}-\mathrm{THCV}$ in animal models of Parkinson's disease. Br. J. Pharmacol. 2011, 163, 1495-1506. [CrossRef]

31. Alvarez-Fischer, D.; Henze, C.; Strenzke, C.; Westrich, J.; Ferger, B.; Höglinger, G.U.; Oertel, W.H.; Hartmann, A. Characterization of the striatal 6-OHDA model of Parkinson's disease in wild type and alpha-synuclein-deleted mice. Exp. Neurol. 2008, 210, 182-193. [CrossRef] [PubMed]

32. Fleming, S.M.; Ekhator, O.R.; Ghisays, V. Assessment of sensorimotor function in mouse models of Parkinson's disease. J. Vis. Exp. 2013, 76, 50303. [CrossRef] [PubMed] 
33. Alvarez, F.J.; Lafuente, H.; Rey-Santano, M.C.; Mielgo, E.V.; Gastiasoro, E.; Rueda, M.; Pertwee, R.G.; Castillo, I.A.; Romero, J.; Martínez-Orgado, J. Neuroprotective Effects of the Nonpsychoactive Cannabinoid Cannabidiol in Hypoxic-Ischemic Newborn Piglets. Pediatr. Res. 2008, 64, 653-658. [CrossRef] [PubMed]

34. Ceprián, M.; Jiménez-Sánchez, L.; Vargas, C.; Barata, L.; Hind, W.; Martínez-Orgado, J. Cannabidiol reduces brain damage and improves functional recovery in a neonatal rat model of arterial ischemic stroke. Neuropharmacology 2017, 116, 151-159. [CrossRef] 